Corina Curtis Migración y Discriminación en la Argentina: Un diagnostico participativo.

\title{
Migración y discriminación en La ARgentina: UN DIAGNÓSTICO PARTICIPATIVO
}

\author{
Corina Courtis \\ Pasaje Graciela 5436 - Ñuñoa - Santiago \\ corinacourtis@yahoo.com.ar \\ Universidad de Buenos Aires -CONICET \\ Argentina
}

\section{Resumen}

Esta ponencia presenta un diagnóstico participativo sobre discriminación llevado a cabo entre 2007 y 2009 para una organización no gubernamental argentina (Asociación por los Derechos Civiles $A D C)$. El diagnóstico abordó diversos colectivos nacionales, étnicos y religiosos del Área Metropolitana de Buenos Aires en cuya construcción la migración es o fue un factor de marcación (inmigración boliviana y coreana, refugiados, pueblo Gitano, colectividades árabe y judía). El estudio buscó indagar situaciones y patrones de discriminación, percepciones sobre discriminación y acciones comunitarias vinculadas a la anti-discriminación. Con el fin de lograr un diagnóstico que registrara las diferentes y divergentes voces "comunitarias", el trabajo de investigación y recolección de casos se realizó conjuntamente con referentes de los colectivos mencionados. Esta modalidad participativa despierta interrogantes e impone desafíos que ameritan una reflexión. De allí que esta presentación discurra en una doble clave: la exposición de algunos resultados del diagnóstico y la narración de su diseño metodológico y de su puesta en marcha.

PALABRAS CLAVE: discriminación étnica/nacional/religiosa; diagnóstico participativo; Argentina

\section{Summary}

This communication presents a participatory diagnosis on discrimination carried out between 2007 and 2009 for an Argentine non-governmental organization (Association for Civil Rights - ADC). The diagnosis dealt with various national, ethnic and religious collectives from Greater Buenos Aires in whose construction migration is or has been a "marking" factor (Bolivian and Korean immigration, refugees, Rom people, Arab and Jewish communities). The study aimed to explore situations and 
Corina Curtis Migración y Discriminación en la Argentina: Un diagnostico participativo.

patterns of discrimination, discrimination perceptions and collective actions against it. In order for the diagnosis to grasp different and divergent "community" voices, research and case- compilation activities were undertaken jointly with referents of the selected groups. The participatory approach adopted poses questions and challenges that deserve to be reflected upon. Therefore, the presentation of the diagnosis is conveyed in a double key: the exhibition of some of its outputs, and the narrative account of its methodological design and development.

KEY WORDS: ethnic/national/religious discrimination; participatory diagnosis, Argentina

\section{Introducción}

La Asociación por los Derechos Civiles (ADC) es una organización no gubernamental abocada a promover y defender derechos fundamentales a través de una serie de estrategias combinadas: sensibilización, seguimiento, lobby, litigio estratégico. Mediante el litigio estratégico, la Asociación ha judicializado casos de interés colectivo que sentaron precedentes y jurisprudencia para la presentación y resolución de casos individuales. Entre ellos, la ADC patrocinó una serie de casos de discriminación laboral por género y por nacionalidad que sugirieron la posibilidad de expandir el trabajo en torno a la temática, reforzándolo con la producción y sistematización de información que complementara la perspectiva legal que predomina en la Asociación.

Así, en enero de 2007, y con la contribución de la Fundación Ford, se me propuso, junto a una colega -ambas antropólogas-- la puesta en marcha de un observatorio sobre casos y situaciones de discriminación que afectaran a grupos étnicos, nacionales y religiosos. Sin embargo, la combinación entre el horizonte temporal acotado del proyecto (insuficiente para montar y desarrollar actividades de observatorio) y ciertas imprecisiones del formato propuesto y de sus resultados (conclusión a la que llegamos luego de analizar una decena de observatorios de derechos en Argentina y Chile) nos decidió a llevar adelante, en lugar de un observatorio, un diagnóstico participativo sobre discriminación. 
Corina Curtis Migración y Discriminación en la Argentina: Un diagnostico participativo.

\section{El proceso de trabajo}

En la Argentina, la discriminación es un concepto que se ha incorporado al discurso público en las últimas décadas. Además del carácter constitucional del principio de no discriminación y de la existencia de una ley de migraciones que garantiza una serie de derechos básicos a los extranjeros más allá de su condición migratoria ${ }^{1}$, ya desde fines de la década de 1980 Argentina cuenta con una ley antidiscriminatoria (Ley № 23.592) que aporta una definición positiva de "actos discriminatorios": impedir, obstruir, restringir o de algún modo menoscabar, arbitrariamente, "el pleno ejercicio sobre bases igualitarias de los derechos y garantías fundamentales reconocidos en la Constitución Nacional". Esta restringida acepción jurídica contrasta con el uso cotidiano del término, más amplio, ligado tanto a prácticas de estereotipación discursiva como al trato diferencial. El punto a destacar es que hay una brecha considerable entre el acto discriminatorio en términos jurídicos y la discriminación en tanto que percepción social.

Nuestro diagnóstico se propuso justamente trabajar en ambos planos: la identificación y el registro de casos de discriminación en el sentido jurídico, más estricto, conforme a la definición de la ley antidiscriminatoria y, simultáneamente, la indagación y mapeo de patrones y percepciones de discriminación -es decir: la discriminación como una vivencia/experiencia cotidiana- para lograr un variado mosaico de las situaciones que distintos colectivos perciben como más críticas o de mayor frecuencia, y de las acciones individuales y colectivas encaradas para enfrentarlas.

Con el fin de delimitar los "grupos" a abordar, se tuvo en cuenta el juego de diversos elementos: origen nacional, pertenencia/auto-atribución étnica, adscripción religiosa, antigüedad de la colectividad en Argentina, ocupación del espacio urbano, destreza en el uso del español, inserción económica/laboral, visibilidad social, organización interna (asociacionismo). Finalmente, se trabajó con seis colectivos en cuya construcción la migración es o fue un factor de marcación: la colectividad boliviana, la colectividad coreana, refugiados, Pueblo Rom (Gitano), colectividad árabe (descendientes de árabes islámicos y cristianos) y colectividad judía. 
Corina Curtis Migración y Discriminación en la Argentina: Un diagnostico participativo.

Las colectividades boliviana y coreana, de inmigración relativamente reciente en el Area Metropolitana de Buenos Aires, están integradas por personas nacidas en el extranjero y, a la vez, cuentan entre sus miembros a "bolivianos étnicos" y a "coreanos étnicos": personas nacidas en Argentina pero de padres bolivianos o coreanos. Si bien desde el punto de vista de la normativa nacional estas personas son argentinas ${ }^{2}$, en las interacciones cotidianas suele predominar la lectura fenotípica, que autoriza a muchos de sus ocasionales interlocutores a verlos y tratarlos como si fueran extranjeros. Las colectividades árabe, judía y Rom, con presencia de más larga data en la Argentina, están constituidas de manera predominante por personas nacidas en el país, aunque acusan una incidencia variable -pero reducida- de extranjeros. Las dos primeras tienen una exitosa trayectoria de asociacionismo que hace disponible una gama amplia de recursos culturales, simbólicos y económicos para atender a sus miembros cuando ocurren situaciones de discriminación. "Colectividad gitana" designa a una gran variedad de grupos de diversos orígenes, con idiomas, creencias religiosas y vestimentas diferentes, que se ven unificados tanto por la denominación impuesta por la sociedad mayor (gitanos) como por una tradición -no siempre conservada- de nomadismo. El Pueblo Rom ha sido históricamente objeto de "sospecha", discriminación y prejuicio. En Argentina, estos elementos influyen en las dificultades que estos grupos han encontrado para organizarse como colectividad o como federación de colectividades. Por su parte, todas las personas refugiadas o peticionantes de asilo son extranjeras, y provienen de un amplio espectro de países de África, América Latina, Asia y Europa del Este. No conforman una colectividad en términos étnicos, nacionales o religiosos, pero sí han tenido experiencias de asociacionismo, obligados por el tratamiento que reciben de diversas instancias institucionales y administrativas. Es particularmente sensible el caso de varones refugiados o peticionantes provenientes de África, llegados a Buenos Aires a partir de mediados de 1990. Fenotípicamente muy visibles en una sociedad predominantemente blanca, con el inglés o el francés como lengua de socialización secundaria y, en general, insertos en sectores laborales y habitacionales precarios, han ido construyendo redes y lazos sociales de asistencia mutua que dan pie a una incipiente autopercepción como grupo. 
Corina Curtis Migración y Discriminación en la Argentina: Un diagnostico participativo.

Tanto el registro de casos como la indagación de patrones y percepciones fueron realizados de manera conjunta por consultores "externos" (cientistas sociales y documentalistas con experiencia significativa de trabajo con las poblaciones de referencia) y por consultores "comunitarios", referentes (al menos en la materia que nos ocupa) de estos colectivos. En diálogo con ellos fuimos especificando y diversificando los "productos" del proyecto.

El diagnóstico arrojó una diversidad de productos. Algunos de ellos constituyen materiales más típicos para este tipo de investigación:

- Un libro (Discriminaciones. Un diagnóstico participativo. Buenos Aires: Editores del Puerto, en prensa) en el cual se compila una serie de informes originales sobre percepciones y acciones relativas a la discriminación (en sentido amplio) para cada uno de los colectivos seleccionados, que dan cuenta de los principales patrones de discriminación que los afectan.

- Una página web.

- Documentos para actividades de lobby: a lo largo del proyecto se realizaron actividades de incidencia a través de la elaboración, presentación y discusión de documentos en el ámbito parlamentario. Se participó de la discusión parlamentaria de diferentes iniciativas de reforma de la ley antidiscriminatoria y, en ocasión de las reformas tanto de la Ley Nacional de Tránsito como del Código de Tránsito de la Ciudad de Buenos Aires, se promovió la reflexión sobre el requisito de saber leer el idioma nacional para obtener la licencia de conducir.

Además, el proyecto generó productos quizás menos tradicionales; entre los que se encuentran:

- Dos documentales: "Por ser boliviana" y "Buscando refugio", que fueron reunidos en un CD de difusión que incluye también otros materiales de informativos y de sensibilización para el público general, tales como fichas de casos de aplicación de la ley antidiscriminatoria y los textos de la normativa internacional y nacional relevante en el campo de la discriminación.

- Clippings de noticias periodísticas: se compilaron diversos corpora de noticias periodísticas aparecidas en los principales diarios nacionales en los últimos cinco años, para analizar los 
Corina Curtis Migración y Discriminación en la Argentina: Un diagnostico participativo.

mecanismos por los cuales se realiza discursivamente la discriminación percibida. Dichos corpora constituyen material de archivo de utilidad para cientistas sociales abocados tanto al estudio de la discriminación como del discurso periodístico y las representaciones sobre el "otro".

- Dossiers de casos: también se compilaron y analizaron casos significativos de actos discriminatorios (según la Ley 23.592) como insumo para evaluar una estrategia institucional propia en el campo de la prevención y/o persecución de la discriminación.

- Una experiencia de diálogo entre jóvenes de las colectividades árabe y judía sobre discriminación: se utilizó el formato del diálogo, un modelo de comunicación vigente entre las colectividades árabe y judía, para promover la reflexión entre jóvenes que adscriben a estas colectividades y, a la vez, relevar información sobre las formas de discriminación que los afectan.

A la vez, el proyecto dio productos más bien "atípicos" y que surgieron de iniciativas de los consultores de las colectividades. En primer lugar, una serie de columnas sobre derechos que se publicaron durante 2008 en dos diarios comunitarios, uno boliviano y otro coreano (en lengua coreana), escritas por miembros de las respectivas colectividades. Además, se creó un núcleo barrial de orientación jurídica y social -al que denominamos NUBA- que, a cargo de dos estudiantes de la colectividad boliviana (un abogado y una trabajadora social) brindó asesoramiento sobre derechos y discriminación en un barrio con importante presencia boliviana. El núcleo funcionó a la vez como espacio de capacitación de estos estudiantes, que estuvieron asesorados por ONGs especializadas en el tema. Finalmente, conducido por los mismos jóvenes, se puso en el aire un programa radial, ARUSA - Nuestra voz, centrado también en la difusión de los derechos de las personas extranjeras que residen en Argentina y que se transmitió semanalmente por una radio comunitaria.

\section{Algunos hallazgos}

El diagnóstico puso en evidencia, entre otras cosas, la diversidad de percepciones sobre la discriminación y de estrategias para enfrentarla. Por ejemplo, para la colectividad boliviana en toda interacción con organismos y funcionarios públicos la discriminación es una línea de lectura. La 
Corina Curtis Migración y Discriminación en la Argentina: Un diagnostico participativo.

situación más extrema registrada en este sentido se dio en torno a la negativa de una funcionaria del registro civil de un hospital de anotar a una beba recién nacida como hija de un ciudadano boliviano que no podía acreditar su identidad con documentos vigentes. La situación -en la que la funcionaria del registro civil actuó acorde a la ley y en protección de la menor- estuvo atravesada por maltrato personal y explicaciones confusas respecto de las características de los documentos en juego. Esta dimensión de maltrato predominó en la caracterización del hecho y la funcionaria fue acusada de negarse a realizar la inscripción porque los padres eran bolivianos. La noticia tuvo amplia cobertura en los medios de la colectividad y convocó a diversos actores a intervenir. En el otro extremo, la comunidad gitana reconoce la existencia de situaciones de discriminación pero opta por una estrategia de resolución individual, caso por caso, y de la manera menos ostensible posible. En esta tónica, casos registrados de rechazo de inscripción en servicios médicos prepagos (que tendrían listados de apellidos gitanos para identificar y rechazar solicitudes) se resolvieron apelando a otras empresas pero sin denunciar a la que rechazó sin fundamentos claros. Del mismo modo, situaciones que en las escuelas primarias son consideradas complicadas y discriminatorias (entre otras, que las niñas concurran sin polleras largas o que no hablen español entre sí) se resuelven de un modo que acumula discriminación a futuro: sacando a los niños del sistema escolar.

Más allá de estas percepciones y estrategias diferenciales frente a la discriminación, las voces recogidas en todas las colectividades señalan a los medios de comunicación como uno de los principales propagadores de estereotipos que son discriminatorios en sí y que, a su vez, son reutilizados luego para justificar la discriminación.

El diagnóstico muestra también la recurrencia de prácticas discriminatorias en diversas instancias de la administración pública, la cual aparece como uno de los principales ámbitos de discriminación sistemática. En estos casos la práctica administrativa es contradictoria con una norma de nivel superior (la ley migratoria, la Constitución Nacional, ley antidiscriminatoria, etc.) pero la continuidad de la práctica puede rastrearse en el hecho de que quienes la realizan a menudo justifican o 
Corina Curtis Migración y Discriminación en la Argentina: Un diagnostico participativo.

fundamentan sus actos en estereotipos de amplia difusión mediática. Vale la pena exponer algunas de estas prácticas:

- una empleada pública de una sucursal de la Administración Nacional de Seguridad Social (ANSES) que se niega a iniciar el trámite solicitado por una persona boliviana con su documento para extranjeros en regla, a menos que dicho documento sea acompañado de una constancia que certifique que no es apócrifo;

- la residencia precaria que se extiende a peticionantes de asilo es encabezada por la leyenda "solicitante de refugio";

- la falta de mecanismos claros y uniformes para asegurar la continuidad educativa en el ciclo secundario de niños refugiados;

- un servicio médico de un hospital público que supedita el otorgamiento de un turno y la continuidad de un tratamiento ambulatorio a la presentación de documentación que certifique regularidad migratoria, cuando la ley de migraciones establece el derecho a la salud de la población migrante más allá de su situación migratoria;

- la autorización tácita otorgada a empleados de mostrador de aerolíneas comerciales para hacer controles a pasajeros a partir de directivas de la Autoridad Aeroportuaria de Estados Unidos de América sobre la base de listas de apellidos árabes.

\section{Cierre: el carácter participativo del diagnóstico en perspectiva antropológica}

Sin duda, la incorporación de consultores comunitarios constituyó un desafío y una fuente de aprendizaje para todos los actores involucrados en el proyecto.

La figura del diagnóstico participativo implica el trabajo conjunto con quienes se reconocen como miembros de los grupos seleccionados. Este trabajo conjunto conlleva discutir y acordar conceptualizaciones y abordajes sobre la discriminación. Un punto a tener en cuenta es que los distintos consultores comunitarios de una misma colectividad no necesariamente tienen percepciones $\mathrm{o}$ interpretaciones coincidentes respecto a las situaciones de discriminación. A menudo, estas diferencias de opiniones además abonan estrategias diversas, que van desde la 
Corina Curtis Migración y Discriminación en la Argentina: Un diagnostico participativo.

hiper-visibilidad hasta la invisibilización y la solución discreta y caso a caso de actos discriminatorios. Entendemos que recuperar y evidenciar esta diversidad de puntos de vista es central para comprender, evaluar y diseñar acciones anti-discriminatorias.

Por otra parte, el trabajo en conjunto conlleva, al menos, acomodar expectativas, tiempos y plazos de trabajo, y consensuar criterios de recolección, sistematización y presentación de información. Básicamente, esta modalidad de trabajo implica que la "tradicional tarea científica / académica" es realizada de manera conjunta con el "tradicional objeto de investigación". En este sentido, para las coordinadoras antropólogas, el encuentro con el consultor comunitario en/para el trabajo se constituye en "campo". O mejor, el trabajo deviene campo, y uno especialmente desafiante por, al menos, dos razones. En primer lugar, sustrae al "otro" de ámbitos etnicizados o exóticos y lo reubica como agente en un espacio familiar para el antropólogo: allí, en la poco tradicional circulación del "otro" como (putativo) par en el escenario profesional antropológico, también debe operar la mirada etnográfica, no ya para generar contenidos del diagnóstico sino para identificar las mencionadas brechas y percibir apropiaciones o impugnaciones del encuadre laboral impuesto. En segundo lugar, este campo impone a la reflexión etnográfica una agilidad particular, un vuelco inmediato sobre la acción que permita calibrar los vaivenes del trabajo intercultural. $\mathrm{Y}$, sobre todo, que permita imaginar sobre la marcha alternativas más plenamente participativas. 
Corina Curtis Migración y Discriminación en la Argentina: Un diagnostico participativo.

${ }^{1}$ Ley de Migraciones $N^{\circ} 25.871$, promulgada en 2004.

${ }^{2}$ La ley da preferencia al criterio jus soli de atribución de ciudadanía, sin excluir el de jus sanguini para hijos/as de nacionales nacidos en el exterior. 